\title{
Knowledge and perceptions of prescribers regarding adherence to standard treatment guidelines for malaria: a comparative cross-sectional study from Pakistan
}

\author{
M. Malik, ${ }^{1,2}$ M.A.A. Hassali, ${ }^{1}$ A.A. Shafie ${ }^{1}$ and A. Hussain ${ }^{2}$
}

$$
\begin{aligned}
& \text { معارف ومدركات محرري الوصفات الطبية حول الالتزام بالدلائل الإرشادية العلاجية المعيارية للملاريا: دراسة مقارنة مستعرضة }
\end{aligned}
$$

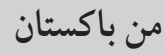

$$
\begin{aligned}
& \text { مديحة مالك، محمد عزمي أحمد حسالي، عسرول أكمل شافعي، أزهر حسين } \\
& \text { الخلاصة: على الرغم من تو افر الدلائل الإرشادية العلاجية المعيارية للملاريا في باكستان فإن التزام محرري الوصفات بها سيء. وتستهدف هذه الماته }
\end{aligned}
$$

ABSTRACT Despite the availability of standard treatment guidelines for malaria in Pakistan adherence to protocols by prescribers is poor. This descriptive, cross-sectional study aimed to explore the perceptions and knowledge of prescribers in Islamabad and Rawalpindi cities towards adherence to standard treatment guidelines for malaria. A questionnaire was distributed to a random sample of 360 prescribers; $64.7 \%$ were satisfied with the available antimalarial drugs and $41.3 \%$ agreed that antimalarial drugs should only be prescribed after diagnostic testing. Only half the prescribers had the guidelines available in their health facility. Almost all the prescribers (97.7\%) agreed that there was a need for more educational programmes about the guidelines. Most prescribers were unaware of the correct standard treatment regimen for Plasmodium falciparum and $P$. vivax malaria. There were no differences in knowledge between males and females, but prescribers having more experience, practising as general practitioners and working in private health-care facilities possessed significantly better knowledge than their counterparts.

Connaissances et perceptions des prescripteurs concernant les guides thérapeutiques normalisés pour le paludisme et le respect de ces derniers : étude transversale comparative menée au Pakistan

RÉSUMÉ Malgré la disponibilité de guides thérapeutiques normalisés pour le paludisme au Pakistan, le respect des protocoles de soins par les prescripteurs est médiocre. La présente étude descriptive et transversale visait à explorer les connaissances des prescripteurs dans les villes d'Islamabad et de Rawalpindi concernant les guides thérapeutiques normalisés pour le paludisme et leurs perceptions du respect de ces guides. Un questionnaire a été distribué à un échantillon aléatoire de 360 prescripteurs ; 64,7\% étaient satisfaits des médicaments antipaludiques disponibles et 41,3\% convenaient que les antipaludéens devaient être prescrits uniquement après un test diagnostique. Seule la moitié des prescripteurs possédaient les guides thérapeutiques sur leur lieu de travail. Presque tous les prescripteurs $(97,7 \%)$ convenaient que davantage de programmes d'éducation sur ces guides étaient nécessaires. La plupart des prescripteurs ignoraient les bons schémas thérapeutiques types pour le paludisme à Plasmodium falciparum et $P$. vivax. Aucune différence n'a été observée entre les connaissances des hommes et des femmes. Toutefois, les prescripteurs chevronnés, ceux exerçant comme médecins généralistes et travaillant dans des établissements de soins de santé privés avaient de bien meilleures connaissances que leurs confrères. 


\section{Introduction}

Irrational use of drugs has become a serious problem in developing countries. One of the causes of irrational drug use is the absence and/or lack of implementation of standard treatment guidelines (STGs) for the most common diseases in these countries [1]. This has resulted in prescribing and dispensing of different drugs for the same disease, resulting in non-uniform treatment. STGs are one of the tools to support effective clinical practice and promote the rational use of drugs. Treatment guidelines are designed with the collective opinion of a wide group of recognized national experts and are used as a guide to treatment choices and also as a reference book to help in the overall management of patients [2]. In the case of malaria several studies have reported inappropriate prescribing practices in both public and private health-care facilities due to lack of adherence of prescribers with the STGs [3-6]. Other studies have reported improved case management after implementation of STGs, but have shown little impact on prescribing habits due to lack of follow up on the implementation of these guidelines [7-9]. Rational prescribing requires that prescribers follow a standard process of prescribing in accordance with STGs, which enables a consistent, therapeutically effective and economically efficient use of drugs. In turn, prescribers' professionalism and commitment to conforming to the criteria for rational drug use has a positive influence on the compliance of patients and outcome of therapy [10].

National treatment guidelines for malaria in Pakistan were designed and published in 2005, through collaborative efforts of the Pakistan Directorate of Malaria Control, the World Health Organization and a technical core group [11]. The guidelines included diagnostic criteria, choice of drug treatment, follow-up and measures to be taken for prevention and control for malaria. The treatment for uncomplicated malaria includes chloroquine + premaquine for the treatment of malaria caused by Plasmodium vivax, or artesunate + sulphadoxine/pyrimathamine for the treatment of $P$. falciparum malaria. Chloroquine is recommended as first-line drug in the treatment of all types of malaria if laboratory diagnosis is not confirmed, while artemether/lumefentrine is recommended as the first-line drug only for confirmed cases of P. falciparum.

Despite the introduction of STGs the country, most medical practitioners in Pakistan are inclined to practice their own protocols to treat malaria rather than adhering to standard regimens $[12,13]$. This might eventually lead to the emergence of higher rates of resistance to antimalarial drugs in the country [14]. The main objective of the present study was to explore the perceptions and knowledge of prescribers towards adherence to national STGs for malaria in 2 cities of Pakistan.

\section{Methods}

\section{Study design}

A descriptive, cross-sectional study design was used to evaluate the knowledge and perceptions of prescribers regarding adherence to standard treatment regimen for malaria in the 2 major cities of Pakistan: Islamabad (the national capital) and Rawalpindi (its twin city). The study was approved by the Pakistan malaria control programme.

\section{Sampling of facilities and respondents}

This study was conducted from January to March 2011. The study population included prescribers from Islamabad and Rawalpindi. Calculations of sample size were performed using Raosoft ${ }^{\circ}$ sample size calculator to determine the size of sample that represents the population of registered prescribers [15]. Considering the current population of registered prescribers $(N=5615)$, a sample size of 360 was required to achieve $95 \%$ confidence level with 5\% margin of error. A sample of 360 prescribers was selected randomly from the 2 cities (180 prescribers per city). The prescribers were contacted and given an explanation of the purpose of the study, and their verbal consent to participate in the study was obtained. None of the prescribers refused to participate in the study.

\section{Study tool}

A questionnaire was developed through focus group discussions by using the national STGs for malaria as a reference. Two focus group discussions were carried out at different time intervals with 4 different groups of experts including malariologists and clinicians working at the malaria control programme, specialists, physicians and doctors from academia. Each group comprised 3-4 participants for the development, finalization, face and content validity of the data collection tool. Pilot testing was carried out on 38 prescribers (10\%) of the total sample size before beginning the final study. A Cronbach alpha value of 0.72 confirmed the reliability and internal consistency of the questionnaire.

The questionnaire comprised 5 sections. The first section included information regarding prescriber's demographic characteristics: sex, city, sector (public/private), type of health facility, profession and years of experience. In the second section, perceptions of prescribers regarding current treatment practices for malaria in the country were explored. In the third section the perceptions of prescribers regarding contributing factors towards lack of adherence to STGs were explored, including patient-related factors, availability and accessibility of the guidelines for reference, prescriber's experience/personal preference and lack of guideline enforcement. Sections 2 and 3 of the questionnaire included a set of statements in which respondents were asked to indicate their level of agreement 
using a 4-point Likert scale where 1 = strongly disagree, 2 = disagree; 3 = agree and 4 = strongly agree. A 4-point Likert scale was used in order to avoid confusion with neutral responses. In the fourth section, the perceptions of prescribers regarding the effectiveness of different currently available antimalarial drugs were explored. In the last section, the knowledge of prescribers regarding standard treatment regimens for malaria was assessed in 2 subscales. Responses were assigned as $1=$ yes $/$ correct and 2 $=$ no/incorrect. Subscale 1 included 2 questions regarding standard treatment regimens for $P$. vivax (score 2-4) while subscale 2 included 4 questions regarding standard treatment regimens for $P$. falciparum (score 4-8). The composite score range was 6-12 and a lower score indicated better knowledge.

\section{Data collection}

Two teams, one in each city, with 10 data collectors in each team, were trained by the group of experts including the principal investigator. The questionnaire was hand-delivered to prescribers by the data collectors. Informed and verbal consent for participation was taken from the respondents. Respondents were assured about the confidentiality of information verbally and were shown an undertaking signed by the principal investigator. The questionnaire was self-completed by the prescribers and was collected from them on the same day.

\section{Data analysis}

The data were computed and analysed using SPSS, version 16 program and descriptive analysis was conducted. The results of each item in the questionnaire were reported as percentages and frequencies. The Kruskal-Wallis test $(P \leq 0.05)$ was used to compare the knowledge scores of prescribers about standard malaria regimens by profession, length of experience and type of health-care facility, and the MannWhitney test $(P \leq 0.05)$ was used to compare the knowledge of prescribers by sex, sector and city.

\section{Results}

\section{Background characteristics}

Out of 360 prescribers, $62.2 \%$ were male while $37.8 \%$ were female (Table 1). Just over two-thirds (68.1\%) of the total prescribers were working in the public sector, while $31.9 \%$ were from the private sector. A total of $72.2 \%$ were working in tertiary health-care facilities (providing specialized health care in large research and teaching hospitals), $2.2 \%$ in secondary health-care facilities (Tehsil headquarters and district headquarter hospitals), 5.0\% in basic health units (providing primary health care services including health protection and promotion services) and 20.6\% were from private clinics. Cases were referred from lower to higher level (primary to tertiary) depending on the severity of problem and the available infrastructure. Of the total prescribers $20.6 \%$ were house officers, $56.9 \%$ medical officers, $7.5 \%$ specialists and $15.0 \%$ general practitioners. Regarding the experience of the prescribers, $20.3 \%$ had working experience of < 1 year, $42.8 \%$ had $1-5$ years, $22.2 \%$ had $6-10$ years and $14.7 \%$ had $>10$ years.

\section{Satisfaction with available antimalarial drugs}

The results highlighted that $64.7 \%$ of the prescribers were satisfied with the currently available antimalarial drugs and $41.3 \%$ agreed that prescribing antimalarial drugs after performing a diagnostic test was beneficial in the management of malaria. Just over half (56.3\%) of the prescribers reported the absence of STGs for malaria in their health-care facility and $94.1 \%$ agreed that prescribing from the STGs was cost-effective. The great majority of prescribers (97.7\%) agreed that there was a need for more educational programmes to increase knowledge and awareness

\begin{tabular}{lcc}
\hline Table 1 Background characteristics of the sample of prescribers $(\boldsymbol{n}=\mathbf{3 6 0})$ & \\
Variable & No. & $\%$ \\
Sex & & \\
$\quad$ Male & 224 & 62.2 \\
Female & 136 & 37.8 \\
Sector & & \\
$\quad$ Public & 245 & 68.1 \\
Private & 115 & 31.9 \\
Type of health facility & & \\
Tertiary hospital & 260 & 72.2 \\
Secondary hospital & 8 & 2.2 \\
Basic health unit & 18 & 5.0 \\
Private clinic & 74 & 20.6 \\
Profession & & \\
Specialist & 27 & 7.5 \\
Medical officer & 205 & 56.9 \\
House officer & 74 & 20.6 \\
General practitioner & 54 & 15.0 \\
Experience (years) & & \\
$<$ 1 & 73 & 20.3 \\
1-5 & 154 & 42.8 \\
6-10 & 80 & 22.2 \\
$\quad$ 10 & 53 & 14.7 \\
\hline
\end{tabular}




\begin{tabular}{|c|c|c|c|c|c|c|c|c|}
\hline \multirow[t]{3}{*}{ Item } & \multicolumn{8}{|c|}{ Prescribers' opinions $(n=360)$} \\
\hline & \multicolumn{2}{|c|}{ Strongly disagree } & \multicolumn{2}{|c|}{ Disagree } & \multicolumn{2}{|c|}{ Strongly agree } & \multicolumn{2}{|c|}{ Agree } \\
\hline & No. & $\%$ & No. & $\%$ & No. & $\%$ & No. & $\%$ \\
\hline $\begin{array}{l}\text { Malaria is well controlled with the current } \\
\text { available antimalarial drugs in Pakistan }\end{array}$ & 15 & 4.2 & 112 & 31.1 & 207 & 57.5 & 26 & 7.2 \\
\hline $\begin{array}{l}\text { National standard malaria treatment guidelines } \\
\text { are available in the health facility }\end{array}$ & 188 & 52.2 & 15 & 4.2 & 77 & 21.4 & 80 & 22.2 \\
\hline $\begin{array}{l}\text { Prescribing antimalarials before performing } \\
\text { diagnostic test is beneficial in the management } \\
\text { of malaria }\end{array}$ & 31 & 8.6 & 180 & 50.0 & 75 & 20.8 & 74 & 20.6 \\
\hline $\begin{array}{l}\text { Prescribing antimalarial drugs for malaria } \\
\text { according to the guidelines are cost-effective }\end{array}$ & 10 & 2.8 & 11 & 3.1 & 215 & 59.7 & 124 & 34.4 \\
\hline $\begin{array}{l}\text { There is a need for more educational } \\
\text { programmes to increase knowledge and } \\
\text { awareness on the available malaria treatment } \\
\text { guidelines }\end{array}$ & 1 & 0.3 & 7 & 1.9 & 142 & 39.4 & 210 & 58.3 \\
\hline
\end{tabular}

about the available treatment guidelines for malaria (Table 2).

\section{Factors affecting lack of adherence}

A majority of prescribers were of the view that patient-related factors (93.8\%), availability of STGs for reference (98.6\%), lack of awareness of prescribers regarding STGs (70.2\%), prescribers' experience $(95.5 \%)$ and lack of enforcement of STGs for malaria (97.5\%) were the main factors contributing towards lack of adherence to STGs in the management of malaria in Pakistan (Table 3).

\section{Effectiveness of antimalarial drugs available}

Most of the prescribers were of the view that artemisinin-based combination therapy (ACT) (89.7\%), chloroquine
+ primaquine (89.7\%) and primaquine $0.75 \mathrm{mg} / \mathrm{kg}(82.2 \%)$ were the most effective antimalarial drugs available in Pakistan for management of malaria. Single-dose primaquine +ACT (77.2\%) and dihydroartemisinin + piperaquine (40.3\%) were considered the least effective antimalarial drugs (Table 4).

\section{Prescribers' knowledge about standard treatment regimens}

Most of the prescribers were unaware of the correct standard treatment regimens for $P$. falciparum and $P$. vivax malaria. Only $66.4 \%$ of the prescribers were aware about the correct regimen for chloroquine and $23.3 \%$ knew the correct regimen for premaquine used for treatment of $P$. vivax malaria. On the other hand, $74.7 \%$ knew the correct regimen for artemether/lumefentrine and $35.3 \%$ were aware about the regimen for artesunate used for treatment of $P$. falciparum malaria (Table 5).

The composite scores for knowledge were taken into account when assessing the knowledge of prescribers for the whole therapeutic regimen. The median score for overall knowledge of prescribers regarding the malaria treatment regimen was 10 (range 6-12), for the treatment regimen for $P$. vivax it was 3 (range 2-4) and for $P$. falciparum it was 7 (range 4-8).

Significant differences were found in the knowledge scores of prescribers between those in the public and private sector and between the 2 cities, while no significant difference was found between the sexes $(P<0.05$, MannWhitney test). Prescribers working in the private sector had comparatively better knowledge about the standard

\begin{tabular}{|c|c|c|c|c|c|c|c|c|}
\hline \multirow[t]{3}{*}{ Factor } & \multicolumn{8}{|c|}{ Prescribers' perceptions $(n=360)$} \\
\hline & \multicolumn{2}{|c|}{ Strongly disagree } & \multicolumn{2}{|c|}{ Disagree } & \multicolumn{2}{|c|}{ Strongly agree } & \multicolumn{2}{|c|}{ Agree } \\
\hline & No. & $\%$ & No. & $\%$ & No. & $\%$ & No. & $\%$ \\
\hline Patient-related factors & 1 & 0.3 & 21 & 5.8 & 261 & 72.5 & 77 & 21.4 \\
\hline Availability of STGs for reference & 1 & 0.3 & 4 & 1.1 & 235 & 65.3 & 120 & 33.3 \\
\hline Lack of awareness regarding STGs & 2 & 0.6 & 5 & 1.4 & 205 & 56.9 & 148 & 41.1 \\
\hline Prescribers' experience & 4 & 1.1 & 12 & 3.3 & 155 & 43.1 & 189 & 52.5 \\
\hline Lack of STGs enforcement & 1 & 0.3 & 8 & 2.2 & 172 & 47.8 & 179 & 49.7 \\
\hline
\end{tabular}




\begin{tabular}{|c|c|c|c|c|}
\hline \multirow[t]{3}{*}{ Antimalarial drug } & \multicolumn{4}{|c|}{ Prescribers' perceptions $(n=360)$} \\
\hline & \multicolumn{2}{|c|}{ Least effective } & \multicolumn{2}{|c|}{ Most effective } \\
\hline & No. & $\%$ & No. & $\%$ \\
\hline Artemisinin-based combination therapy (ACT) & 37 & 10.3 & 323 & 89.7 \\
\hline Dihydroartemisinin + piperaquine & 145 & 40.3 & 215 & 59.7 \\
\hline Artesunate + tetracycline/ doxycycline/ clindamycin & 88 & 24.4 & 272 & 75.6 \\
\hline Single-dose primaquine $+\mathrm{ACT}$ & 278 & 77.2 & 82 & 22.8 \\
\hline Primaquine $0.75 \mathrm{mg} / \mathrm{kg}$ body weight & 64 & 17.8 & 296 & 82.2 \\
\hline Chloroquine + primaquine & 37 & 10.3 & 323 & 89.7 \\
\hline $\mathrm{ACT}+$ primaquine & 87 & 24.2 & 273 & 75.8 \\
\hline
\end{tabular}

treatment regimen for malaria than those in the public sector and those in Rawalpindi had better knowledge than in Islamabad (Table 6). Prescribers working as specialists had significantly better knowledge than other professions, while those with more years of experience and those practising as specialists had better knowledge $(P<0.05$, Kruskal-Wallis test).

\section{Discussion}

Most of the medical practitioners in developing countries including Pakistan are inclined to practise their own protocols to treat malaria rather than adhering to standard regimens [12]. The results of the present study showed that most of the prescribers agreed that the absence of STGs for malaria in their health-care facilities, lack of awareness of prescribers regarding STGs, prescribers' experience and lack of enforcement of STGs were the main factors contributing to irrational treatment practices for malaria in Pakistan. The results of the present study were in line with a study conducted in Nigeria, which showed similar findings in terms of irrational prescribing practices due to lack of adherence to national treatment guidelines although they did not link this to the development of resistance [16].

The results of the present study highlighted that most of the prescribers were satisfied with the currently available antimalarial drugs, although little data regarding the resistance of currently available antimalarial drugs have been reported in Pakistan. However, poor vector control, limited access to antimalarial drugs, lack of laboratory investigation and lack of a national database for registering the actual number of malaria cases in different provinces of Pakistan might be the main factors contributing to the high prevalence of malaria in the country [13]. Around half of prescribers also agreed that prescribing of antimalarial drugs after performing a diagnostic test is beneficial in the management of malaria. It was observed that prescribing of antimalarial drugs after laboratory confirmation significantly decreased the total number of prescriptions in Malawi [17]. ACT was the most effective antimalarial

\begin{tabular}{|c|c|c|c|c|}
\hline \multirow[t]{3}{*}{ Antimalarial treatment } & \multicolumn{4}{|c|}{$\begin{array}{c}\text { Prescribers' knowledge about } \\
\text { standard treatment regimen }(n=360)\end{array}$} \\
\hline & \multicolumn{2}{|c|}{ Correct } & \multicolumn{2}{|c|}{ Incorrect } \\
\hline & No. & $\%$ & No. & $\%$ \\
\hline \multicolumn{5}{|l|}{ Standard treatment regimen for Plasmodium vivax malaria } \\
\hline $\begin{array}{l}\text { Chloroquine }\left(150 \mathrm{mg} / \mathrm{kg} 4 \times \text { day } 1 \& 2,2 \times 3^{\text {rd }} \text { day }\right) \text { for } 3 \text { days + primaquine }(0.25 \mathrm{mg} / \mathrm{kg} \\
1 \times \text { per day) for } 14 \text { days }\end{array}$ & 239 & 66.4 & 121 & 33.6 \\
\hline Primaquine $(0.75 \mathrm{mg} / \mathrm{kg}$ body weight $1 \times$ per week) for 8 weeks & 84 & 23.3 & 276 & 76.7 \\
\hline \multicolumn{5}{|l|}{ Standard treatment regimen for Plasmodium falciparum malaria } \\
\hline Artemether (20 mg per day) + lumefantrine (120 mg 2× per day) for 3 days & 269 & 74.7 & 91 & 25.3 \\
\hline Artesunate $(20 \mathrm{mg} / \mathrm{kg} 1 \times$ per day $)+$ tetracycline $(4 \mathrm{mg} / \mathrm{kg} 4 \times$ per day $)$ for 7 days & 127 & 35.3 & 233 & 64.7 \\
\hline Dihydroartemisinin ( $4 \mathrm{mg} / \mathrm{kg}$ per day) + piperaquine $(18 \mathrm{mg} / \mathrm{kg}$ per day) for 3 days & 122 & 33.9 & 238 & 66.1 \\
\hline Single-dose piperaquine $(0.75 \mathrm{mg} / \mathrm{kg})$ equivalent to ACT & 102 & 28.3 & 258 & 71.7 \\
\hline
\end{tabular}

$A C T=$ artemisinin-based combination therapy. 
drug for the management of malaria in Pakistan according to almost 90\% of our respondents. The results of the study are in line with another study which showed predominately use of ACT for the treatment of malaria in Nigeria [18].

The overall knowledge of prescribers regarding standard treatment regimens for malaria was inadequate in Pakistan. Most of the prescribers were unaware of the correct standard treatment regimen for the treatment of P. falciparum and P. vivax. This might be due to the lack of implementation of STGs for malaria in the country. The results of the present study confirm the findings of a study in Cambodia, which concluded that the high rate of inappropriate prescriptions for malaria are mostly due to lack of or inappropriate doses, frequency, dosages and duration of treatment [19].

We found no difference between male and female prescribers in knowledge regarding the standard treatment regimen for malaria, although prescribers working in the private sector and in Rawalpindi had comparatively better knowledge than public sector workers and those in Islamabad, the capital. This might be due to the fact that a greater proportion of the population visit the private sector for treatment. Previous studies have reported many problems associated with prescribing practices in both public and private health-care facilities and both private and public practitioners usually do not comply with the STGs $[16,20]$.
The present study highlighted that prescribers having more experience and working as specialists possessed relatively better knowledge about malaria treatment. These results are in line with another study which also showed specialists to be more knowledgeable about care in general, as they use medications associated with improved survival, comply with STGs and use more resources including diagnostic tests and procedures [21]. In our study general practitioners had comparatively better knowledge regarding standard treatment regimen for malaria than their counterparts. This might be due to the fact that most of the specialists are working as general practitioners running their own private clinics in the evening in Pakistan. General practitioners are

\begin{tabular}{|c|c|c|c|c|}
\hline Variable & No. & Median knowledge score & Test statistic & $P$-value \\
\hline Sex & & & $15081^{\mathrm{a}}$ & 0.438 \\
\hline Male & 224 & 10 & & \\
\hline Female & 136 & 10 & & \\
\hline \multicolumn{5}{|l|}{ City } \\
\hline Islamabad & 180 & 9 & $14177^{a}$ & \multirow{2}{*}{0.019} \\
\hline Rawalpindi & 180 & 10 & & \\
\hline Sector & & & $9330^{\mathrm{a}}$ & $<0.001$ \\
\hline Public & 245 & 10 & & \\
\hline Private & 115 & 9 & & \\
\hline Type of health facility & & & $26.72^{\mathrm{b}}$ & $<0.001$ \\
\hline Tertiary hospital & 260 & 10 & & \\
\hline Secondary hospital & 8 & 9.5 & & \\
\hline Basic health unit & 18 & 9.5 & & \\
\hline Private clinic & 74 & 9 & & \\
\hline Profession & & & $56.79^{\mathrm{b}}$ & $<0.001$ \\
\hline Specialist & 27 & 9 & & \\
\hline Medical officer & 205 & 10 & & \\
\hline House officer & 74 & 8.5 & & \\
\hline General practitioner & 54 & 9 & & \\
\hline Experience (years) & & & $38.65^{\mathrm{b}}$ & $<0.001$ \\
\hline$<1$ & 73 & 10 & & \\
\hline $1-5$ & 154 & 10 & & \\
\hline 6-10 & 80 & 9 & & \\
\hline$>10$ & 53 & 9 & & \\
\hline Total & 360 & 10 & - & - \\
\hline
\end{tabular}

${ }^{a}$ Mann-Whitney test; ${ }^{b}$ Kruskal-Wallis test. 
usually the main prescribers of antimalarial drugs due to the ease of access to their services and affordability for a large proportion of the population. This illustrates the potential role of general practitioners in determining prescribing patterns. Thus attention should be focused on training of this group of prescribers in future interventions or when there are modifications or updates to the national antimalarial drugs policy [22]. Almost all of the prescribers in our survey were of the view that there is a need for more educational programmes to increase knowledge and awareness about the STGs. The influence of inappropriate prescribing of antimalarial drug on development of drugs resistance in malaria highlights the need to improve malaria treatment practices through well organized and planned health education training programmes of prescribers $[23,24]$.

The study was conducted in only 2 cities of Pakistan and the results of the study may not be generalizable to other parts of the country. Unavailability of a national updated database for registered malaria cases in Pakistan, financial and logistic constraints and political turmoil in the country were some of the problems faced during the conduct of the study.

\section{Conclusions}

The overall knowledge of prescribers regarding standard treatment regimens for malaria in the 2 cities of
Pakistan was inadequate. Most of the prescribers were unaware of correct standard treatment regimens for the treatment of $P$. falciparum and P. vivax. Prescribers having more experience, practising as general practitioners and working in private health-care facilities possessed comparatively better knowledge. This indicates the potential to promote rational drug use in the private sector even though the public sector is generally targeted for interventions. Innovative approaches are needed to promote and implement STGs in the country to improve the knowledge and adherence of prescribers in the hope that this will result in better practices and control of malaria in Pakistan.

Competing interests: None declared.

\section{References}

1. Chapman S, Durieux P, Walley T. Good prescribing practice. In: Mossialos E, Mrazek M, Walley T, eds. Regulating pharmaceuticals in Europe: striving for efficiency, equity, and quality. Milton Keynes, United Kingdom, Open University Press, 2004.

2. Le Grand A, Hogerzeil HV, Haaijer-Ruskamp FM. Intervention research in rational use of drugs: a review. Health Policy and Planning, 1999, 14:89-102.

3. Abuaku BK, Koram KA, Binka FN. Antimalarial prescribing practices: a challenge to malaria control in Ghana. Medical Principles and Practice, 2005, 14:332-337.

4. Mannan AA, Malik EM, Ali KM. Antimalarial prescribing and dispensing practices in health centres of Khartoum state, 2003-04. Eastern Mediterranean Health Journal, 2009, 15:122128.

5. Meremikwu M et al. Antimalarial drug prescribing practice in private and public health facilities in South-east Nigeria: a descriptive study. Malaria Journal, 2007, 6:55.

6. Ogwal-Okeng JW et al. A comparison of prescribing practices between public and private sector physicians in Uganda. East African Medical Journal, 2004, (Suppl.):S12-S16.

7. Wahlström R et al. Effectiveness of feedback for improving case management of malaria, diarrhoea and pneumonia-a randomized controlled trial at provincial hospitals in Lao PDR. Tropical Medicine and International Health, 2003, 8:901-909.

8. Buabeng KO et al. Self-reported use of anti-malarial drugs and health facility management of malaria in Ghana. Malaria Journal, 2007, 6:85.

9. Laing R, Hogerzeil H, Ross-Degnan D. Ten recommendations to improve use of medicines in developing countries. Health Policy and Planning, 2001, 16:13-20.

10. Chukwuani CM, Onifade M, Sumonu K. Survey of drug use practices and antibiotic prescribing pattern at a general hospital in Nigeria. Pharmacy World and Science, 2002, 24:188-195.

11. National treatment guidelines for malaria, 2005. Islamabad, Pakistan, Ministry of Health, Malaria Control Program Directorate/World Health Organization, 2005.
12. Nizamani A, Kalar NA, Khushk IA. Burden of malaria in Sindh, Pakistan: a two years surveillance report. Journal of Liaquat University of Medical and Health Sciences, 2006, 5(2):76-83.

13. Malik M, Hassali MA, Shaffie AA, Malik M. Standard treatment guidelines for malaria: Challenges in its implementation in Islamabad (federal capital) and Rawalpindi (twin city), Pakistan. Saudi Pharmaceutical Journal, 2013, 21:123-124.

14. Report on the Intercountry Workshop on Monitoring Therapeutic Efficacy of Anti-malarial Drugs, Sana'a, Republic of Yemen, 21-25 April 2002. Cairo, World Health Organization Regional Office for the Eastern Mediterranean, 2002 (WHO-EM/MAL/281/ E/L) (http://whqlibdoc.who.int/emro/2002/WHO-EM_ MAL_281_E_L.pdf, accessed 5 December 2013).

15. Azhar S, Hassali MA, Ibrahim MIM. Doctors' perception and expectations of the role of the pharmacist in Punjab, Pakistan. Tropical Journal of Pharmaceutical Research, 2010, 9(3):205-222.

16. Meremikwu M et al. Antimalarial drug prescribing practice in private and public health facilities in south-east Nigeria: a descriptive study. Malaria Journal, 2007, 6:55.

17. Chitakata R, Khare AK, Blickling C. Prescribing policy for antimalarials [letter]. Africa Health, 1998, 20:2-5, 5.

18. Igboeli NU, Ukwe CV, Ekwunife OI. Increasing use of artemisinin-based combination therapy for treatment of malaria infection in Nigerian hospitals. Pharmacy Practice, 2010, 8(4):243-249.

19. Chareonkul C, Khun VL, Boonshuyar C. Rational drug use in Cambodia: study of three pilot health centers in Kampong Thom Province. Southeast Asian Journal of Tropical Medicine and Public Health, 2002, 33:418-424.

20. Ogwal-Okeng JW et al. A comparison of prescribing practices between public and private sector physicians in Uganda. East African Medical Journal, 2004, 81 (Suppl.):S12-S16.

21. Harrold LR, Field TS, Gurwitz JH. Knowledge, patterns of care, and outcomes of care for generalists and specialists. Journal of General Internal Medicine, 1999, 14:499-511. 
22. McCombie SC. Treatment seeking for malaria: a review of recent research. Social Science and Medicine, 1996, 43:933945.

23. Gbotosho GO et al. Potential contribution of prescription practices to the emergence and spread of chloroquine resistance in south-west Nigeria: caution in the use of artemisinin combination therapy. Malaria Journal, 2009, 8:313.

24. Okeke TA, Uzochukwu BS, Okafor HU. An in-depth study of patent medicine sellers' perspectives on malaria in a rural Nigerian community. Malaria Journal, 2006, 5:97. 